\title{
Para além do transplante hepático: explorando a adesão ao tratamento
}

\section{Beyond liver transplant: exploring adherence to treatment}

\author{
Rafaela Tavares Nóbrega* \\ Universidade Federal do Ceará - UFC, Fortaleza, Ceará, Brasil \\ Marineuza Monteiro da Silva Lucena** \\ Universidade Federal do Ceará - UFC, Fortaleza, Ceará, Brasil
}

\begin{abstract}
RESUMO
Esta pesquisa busca compreender o significado de adesão ao tratamento atribuído por transplantados hepáticos. A Análise de Conteúdo foi utilizada como metodologia para a apreciação dos relatos das entrevistas realizadas com pacientes identificados como não aderentes pela equipe de saúde do Centro de Transplante de Fígado do Ceará. Os pacientes expressaram que a adesão esta relacionada com diversos fatores, como por exemplo, o apoio familiar e o relacionamento com os profissionais de saúde, mas que também é algo que depende "da natureza de cada um". Percebe-se que a forma como lidam com a adesão é a maneira que encontram para incluir em suas vidas as exigências advindas do tratamento. Ao final do artigo, são discutidas estratégias visando à promoção da adesão entre os pacientes.

Palavras-chave: Adesão ao tratamento; Transplante hepático; Promoção da adesão.

ABSTRACT

This research aims to comprehend the meaning of adherence to the treatment, attributed by liver transplant patients. The Analysis of Content was the used methodology to analyze the reports of the interviews with patients who were identified as non-adherents by the health team of the Liver Transplant Center of Ceará. The patients expressed that adherence is related to many factors, for example, as the support of the family and the relationship with health professionals, but it is also something that depends on one's "nature". It is possible to note that the way they deal with adherence is the way they find to include the demands of the treatment in their lives. At last, will be discussed strategies that aim the promotion of adhesion among patients.
\end{abstract}

Keywords: Adherence; Liver transplant; Promoting adherence.

\section{I ntrodução}

As doenças que atingem o fígado comprometem a função hepática que, uma vez afetada, não retornará ao seu estado anterior. 
Progressivamente, tal comprometimento acarreta prejuízos ao organismo do sujeito. O transplante de fígado é um procedimento de alta complexidade que representa a única possibilidade terapêutica no caso de pacientes acometidos por doenças hepáticas, agudas ou crônicas, em estado avançado sem outras possibilidades de tratamento (GARClA, et al., 2005). Nesse procedimento, o órgão danificado é substituído por outro saudável e capaz de realizar sua função adequadamente, de maneira a prolongar a sobrevida do sujeito, proporcionando-lhe melhor qualidade de vida, mesmo sem representar a cura definitiva para a doença de base (RODRIGUES; LIMA; AMORIM, 2004).

Após o transplante é necessário que o paciente tenha acompanhamento médico contínuo, além de fazer uso de medicações imunossupressoras para evitar rejeição e seguir orientações de uma equipe multidisciplinar para garantir o funcionamento adequado do órgão enxertado (RODRIGUES; LIMA; AMORIM, 2004). Essa fase do tratamento apresenta características de uma condição crônica, por implicar restrições dos horários de alimentação de acordo com a medicação, abstinência do consumo de bebidas alcoólicas, exames periódicos, terapia medicamentosa permanente e acompanhamento pela equipe de saúde, além de precipitar vivências estressantes (COSTA; ALVES; LUNARDI, 2006).

Em 2002, o Hospital Universitário Walter Cantídio (HUWC), da Universidade Federal do Ceará, iniciou seu programa de transplantes com doadores cadáveres (GARCIA, et al., 2005), com a inauguração do Centro de Transplantes de Fígado do Ceará (CTFC) que até janeiro de 2010 realizou 427 transplantes.

O CTFC conta com uma equipe multidisciplinar que atua de maneira comprometida com o acompanhamento dos pacientes desde o prétransplante através avaliações para verificar as condições em que se encontram nessa fase de indicação e espera pelo transplante. Depois deste, os cuidados prosseguem, favorecendo a continuidade do processo de melhoria da qualidade de vida advindo com o transplante.

A inserção da psicologia nessa equipe contribui com a análise das condições psicossociais do paciente candidato a receptor de órgão, identificando e abordando aspectos psicológicos relacionados ao transplante e ao tratamento que necessitem ser trabalhados no período pré-transplante. O acompanhamento pós-transplante iniciase desde a sala de recuperação, prolongando-se durante o tempo de internação. Quando da alta hospitalar, o atendimento psicológico ambulatorial acontece de acordo com a demanda decorrente dos atendimentos na enfermaria, a solicitação próprio do paciente ou por encaminhamento da equipe de saúde.

$\mathrm{O}$ adoecimento, a indicação de transplante e o tratamento posterior ao procedimento cirúrgico muitas vezes mobilizam aspectos com os 
quais o paciente, geralmente, não está preparado para lidar (RODRIGUES; LIMA; AMORIM, 2004). Desta forma 0 acompanhamento psicológico pode contribuir nesse momento da vida do indivíduo ajudando-o a desenvolver recursos de enfrentamento.

Assim como o profissional de psicologia, toda a equipe de saúde colabora com a continuidade do tratamento do paciente, ao qual, por sua vez, cabe um papel fundamental para o sucesso do transplante. É necessário seguir corretamente às orientações da equipe de saúde para garantir o funcionamento adequado do órgão transplantado.

Estudos apontam que a não adesão ao tratamento é fator de muitos óbitos entre os pacientes transplantados hepáticos. Coelho, Parolin, Matias, Jorge e Canan Jr. (2003) apontam como causa de $40 \%$ desses óbitos pós-transplante hepático a rejeição crônica, causada pela diminuição ou suspensão do imunossupressor pelo paciente. Outros estudos também referem essas consequências como decorrência da não adesão aos medicamentos (FREDÉRIKS, 2007; STUBER, 2008; CORREIA, 2007; 2008). Desse modo, é inquestionável a importância de se aderir ao tratamento para a garantia da sobrevida do transplantado. Como exposto, a não adesão é causa inclusive de morte entre transplantados hepáticos, assim como em outras populações de pessoas que precisam de tratamento de saúde, por exemplo, hipertensos, diabéticos e outros transplantados.

A Organização Mundial de Saúde trata o conceito de adesão de forma ampla englobando as diversas perspectivas que devem ser observadas. Segundo a referida organização, adesão ao tratamento são ações que vão desde o uso correto das medicações prescritas até medidas de prevenção ao consumo do álcool e tabaco, passando por prática de atividade física, reeducação alimentar e mudanças no estilo de vida. Além disso, inclui a analise da participação do paciente e da equipe multiprofissional como sujeitos ativos no processo do tratamento (WHO, 2003).

Partindo dessa compreensão, percebe-se como necessário o compromisso de todos envolvidos nesse processo, principalmente o próprio paciente, para a promoção da adesão e o prosseguimento adequado do tratamento com vistas à garantia da vida mesmo diante de uma condição de doença crônica.

\section{Metodologia}

Constitui-se como objetivo desse estudo a compreensão dos significados atribuídos à adesão ao tratamento por parte de pacientes transplantados, identificados pela equipe médica como não aderentes (aqueles que não usam adequadamente a medicação prescrita, consomem bebidas alcoólicas, não se submetem à dieta alimentar, ou 
não seguem outras orientações da equipe de saúde). A pesquisa foi aprovada, com o protocolo de número 011.03.09, pelo Comitê de Ética em Pesquisa do HUWC.

Os participantes da pesquisa foram os pacientes que se submeteram à cirurgia de transplante hepático, que seguem em acompanhamento no ambulatório de transplante, identificados como não aderentes ao tratamento por médicos e enfermeiras, e que retornaram para atendimento médico agendado nos meses de março e abril de 2009.

A partir de levantamento prévio junto aos profissionais do CTFC foram identificados 20 pacientes como não aderentes ao tratamento. Destes, 10 tiveram retorno médico no período da pesquisa. Seis pacientes do grupo indicado preencheram os critérios de inclusão para pesquisa, sendo estes: terem sido submetidos ao transplante hepático há mais de três meses da data de levantamento de dados, serem maiores de 18 anos, terem retorno médico marcado para o período das entrevistas e concordarem em participar da pesquisa. Os indivíduos que satisfizeram tais requisitos foram consultados quando à disponibilidade e interesse em participar da pesquisa no mesmo dia em que compareceram ao ambulatório de transplantes para a consulta com o médico. A aceitação de cada um foi registrada com a assinatura do Termo de Consentimento Livre e Esclarecido.

Os critérios de exclusão para não inclusão de sujeitos na pesquisa foram: presença de sinais de transtornos psiquiátricos ou encefalite hepática, ausência de retorno médico agendado para o período citado e falta de disponibilidade para participar. De acordo com as restrições citadas, dois pacientes não participaram por apresentarem transtornos psiquiátricos, enquanto outros dois faltaram ao dia da consulta.

Cinco entrevistas foram utilizadas para a apreciação dos resultados, pois uma destas precisou ser descartada por não ter sido integralmente gravada, em virtude de problemas técnicos com o aparelho de mp3.

Realizada individualmente, com tempo livre, a entrevista para a discussão sobre adesão contou com um roteiro composto por tópicos guia para orientar a discussão dos temas relevantes à problemática pesquisada, sendo esses: a relação estabelecida pelo paciente com o transplante e o tratamento, questionamentos acerca de suas expectativas, sua compreensão sobre o auto-cuidado e seu compromisso com a adesão ao tratamento. O conteúdo das entrevistas foi gravado, posteriormente transcrito e então submetido à análise. O local da pesquisa foi o ambulatório do CTFC do HUWC.

As entrevistas realizadas com os pacientes foram submetidas à análise do conteúdo expresso, segundo o referencial de Bardin (2009). Compreende-se por análise de conteúdo um conjunto de técnicas de comunicação cujo objetivo é que através da sistematização e descrição do conteúdo das mensagens, seja possível 
inferir acerca de conhecimentos referentes à forma da produção e recepção destas mensagens (BARDIN, 2009).

Por meio dessa metodologia é possível compreender o significado atribuído pelo sujeito ao tema em questão. A leitura flutuante é o primeiro passo para a análise dos dados e com o auxílio da leitura de todo o material, categorias relacionadas ao tema foram definidas (GOMES, 2002). Após essa etapa, verificou-se o conteúdo subjacente ao tema em meio ao conteúdo manifesto em cada categoria, considerando o que é geral e aquilo que é particular nas falas dos sujeitos (BARDIN, 2009). Com isso, foi possível a interpretação dos dados, relacionando-se estes com os objetivos do estudo, para, então, chegar aos resultados

\section{Discussão e Resultados}

As características dos participantes da pesquisa são as seguintes:

\begin{tabular}{|l|c|c|c|c|c|}
\hline & Sujeito 1 & Sujeito 2 & Sujeito 3 & Sujeito 4 & Sujeito 5 \\
\hline Idade & 54 anos & 18 anos & 65 anos & 47 anos & 55 anos \\
\hline Sexo & $\mathrm{M}$ & $\mathrm{M}$ & $\mathrm{M}$ & $\mathrm{M}$ & $\mathrm{M}$ \\
\hline Procedencia & $\begin{array}{c}\text { Juazeiro do } \\
\text { Norte - CE }\end{array}$ & Fortaleza - CE & Fortaleza - CE & Fortaleza - CE & Barbalha - CE \\
\hline Estado civil & Casado & Solteiro & Casado & Solteiro & Casado \\
\hline Escolaridade & E.M.* & E.M. & E.M. & E.F.** & Analfabeto \\
\hline Etiologia & Hepatite C & $\begin{array}{c}\text { Hepatite auto- } \\
\text { imune }\end{array}$ & $\begin{array}{c}\text { Cirrose } \\
\text { alcóolica }\end{array}$ & $\begin{array}{c}\text { Cirrose } \\
\text { alcoólica }\end{array}$ & $\begin{array}{c}\text { Cirrose } \\
\text { alcoólica }\end{array}$ \\
\hline $\begin{array}{l}\text { Tempo de pós- } \\
\text { transplante }\end{array}$ & $\begin{array}{c}\text { lanos e } \\
\text { 3meses }\end{array}$ & $\begin{array}{c}\text { 4 anos } \\
\text { anos }\end{array}$ & anos & anos \\
\hline
\end{tabular}

* Ensino Médio ** Ensino Fundamental

Correia, et al. (2007) apontam estudos que verificam a prevalência de adesão ao tratamento considerando os mesmos fatores demográficos como idade, sexo, estado civil, nível socioeconômico e educacional. Os autores afirmam haver concordância entre os estudos que o nível de não adesão é maior em pacientes mais jovens, o que não pode ser afirmado tendo em vista a amostra estudada, uma vez que a maioria dos entrevistados encontra-se na faixa etária de adultos, já próximo à de idosos. Em relação aos outros fatores levantados, pelos autores, os resultados não apresentam um consenso. No tocante aos demais fatores socioeconômicos observados no presente estudo, ressalta-se o fato de todos os participantes da pesquisa serem homens e a maioria destes ter tido indicação de transplante por conta do consumo de bebidas alcoólicas, segunda maior causa de indicações de transplante, segundo Vieira, et al. (2007). 
O discurso dos sujeitos mostra a forma como lidam com o tratamento pós-transplante, como se relacionam com a condição crônica de cuidados imposta pela necessidade de continuidade do acompanhamento pela equipe de saúde, realização de exames periódicos e o uso da medicação. A partir do material obtido nas entrevistas mencionadas foram identificados conteúdos relacionados à adesão ao tratamento. Tais conteúdos foram divididos em três categorias para análise (BARDIN, 2009), quais sejam: apoio familiar, aspectos de adesão (que compreende as subcategorias medicação, consultas, equipe de saúde), e a categoria significado de adesão ao tratamento.

\subsection{Apoio Familiar}

O apoio e a participação familiar foram citados pelos entrevistados como presentes em seus tratamentos e relacionados à adesão. É possível observar essa relação em afirmações de incentivo, acompanhamento às consultas, palavras positivas e até mesmo cobranças referentes ao uso da medicação:

Eles dizem pra eu me recuperar o mais rápido possível, ficar
bom, tão sempre perguntando, essas coisas, né? Mas assim,
quem me acompanha mesmo é a minha esposa. Ela que
sempre vem e fica comigo, quando eu venho pras consultas
ela me acompanha. Ela ta presente sempre. (S.1)
[...] ela [mãe] ta sempre ali, no meu pé [...] Perguntando se
eu tô tomando os remédios (S.2)

O incentivo e apoio dos familiares são considerados fatores importantes desde a indicação de transplante até o momento atual do tratamento. Expressam ainda segurança em determinadas pessoas que se comprometem a acompanhar todo o processo, o que mobiliza os transplantados para seguir as orientações da equipe de saúde. Há expectativas para o prolongamento da vida ao lado de pessoas significativas afetivamente.

De acordo com Romano (1999) a participação familiar diante do adoecimento de um de seus membros é inevitável. Essa interação permanente acontece devido à necessidade de organização constante quando papéis são reestruturados por conta de modificações pessoais. Por gerar uma situação de crise, o adoecimento possibilita essa reestruturação, uma vez que esse acontecimento é vivenciado coletivamente pelos membros da família. Esta precisa buscar estratégias para restaurar o equilíbrio perdido. Diante dessa situação, diversas repercussões emocionais podem ser desencadeadas como a exacerbação de ansiedade, inseguranças, medos por conta da situação de risco e separação física de outros familiares, grupos de amigos e cidade. 
A reorganização familiar por conta do tratamento geralmente é necessária, como a mudança de membros da família, fato que repercute nos que permanecem em outra cidade e nos que acolhem. Além da questão geográfica, os pacientes também abordaram a noção de família como algo que ultrapassa seus laços de sangue, reconhecendo a família da esposa, por exemplo, como sua, por acolhê-los e apoiá-los inclusive durante o adoecimento e tratamento. Felício (2003), ao discorrer sobre o apoio familiar considera a família do cônjuge com sendo a família política, muitas vezes também significativa no processo de apoio ao paciente em tratamento.

\begin{abstract}
A minha família mora em São Paulo. E mora eu, minha esposa, e agora eu estou com a minha mãe que eu trouxe de São Paulo pra cá. A gente tá esperando desocupar uma casinha pra ela. Eu já dei uma casinha pra ela, aí ta esperando. E é só nós dois (esposa), aí tem a família dela que aí é a mãe dela, o pai dela, os irmãos, a família é grande, né? (S.1)
\end{abstract}

A equipe médica também considera a participação familiar como algo importante à adesão, ao solicitar a presença de acompanhantes às consultas quando julga necessário, como exemplificado na fala:

Aí, obrigaram minha mãe a vir pras consultas comigo [...] Obrigaram não, mas acharam que era melhor. Mas pra mim não faz diferença. (S.2)

Em artigo abordando o funcionamento de famílias de pacientes crônicos, Felício (2003) aponta a importância de a equipe de saúde atentar também à família que pode apresentar vulnerabilidade emocional, mas ao mesmo tempo representa uma aliada na promoção da adesão.

Percebe-se que os pacientes entrevistados e os profissionais de saúde do CTFC ressaltaram a participação familiar como um aspecto relevante para adesão pós-transplante. Poucos estudos foram encontrados quanto a esse envolvimento no caso de pacientes adultos. Todavia alguns trabalhos discutem a integração dos familiares ao tratamento no sentido de promover a adesão em pacientes infantis (FREDERICKS, et al., 2007; FERREIRA, 2006). Nestes casos a atuação familiar é considerada essencial para garantir a adesão. Em estudo realizado com famílias de crianças transplantadas hepáticas, Fredericks, et al. (2007) relacionaram a desestruturação familiar à não adesão dos pacientes.

Ferreira (2006) aponta fatores relevantes para a inclusão da família de crianças no tratamento, são eles: a compreensão da doença, o relacionamento dos membros da família entre si e com os profissionais da equipe de saúde, além do estado emocional do 
cuidador da criança. É possível estender alguns dos fatores da adesão pediátrica aos sujeitos adultos, uma vez que é importante que o paciente compreenda sua doença e tenha um bom relacionamento com os profissionais de saúde, pontuando a diferença que nesse caso os próprios pacientes são os principais responsáveis por seu tratamento.

Podemos observar que pacientes, profissionais de saúde e familiares compartilham da opinião que o envolvimento familiar é importante para o incentivo à participação e prosseguimento do tratamento. Embora haja este reconhecimento, de acordo com os entrevistados, a adesão está subordinada a vontade de cada um, depende do próprio sujeito.

[...] aí isso [aderir ao tratamento] depende da natureza das pessoa. Acho que num tem outra coisa pra mudar ele não. Só a natureza da pessoa mesmo. Porque num adianta você falar pra mim "num faça isso", eu num to fazendo agora, mas quando sair daqui eu faço [...] Num adiantou nada. Por isso que eu falo que é da natureza da pessoa. (S.5)

O uso da medicação (LEITE; VASCONCELOS, 2003), a frequência às consultas e o consumo de bebidas alcoólicas são os principais aspectos estudados e discutidos em relação à adesão ao tratamento (ANNUNZIATO, et al., 2007; BERQUISK, et al., 2008; CORREIA, et al., 2007; 2008). Esses aspectos foram abordados espontaneamente pelos pacientes quando convidados a discorrer sobre seu tratamento. Também ressaltaram outros fatores como relação com os profissionais de saúde, limitações relacionadas aos horários da alimentação e efeitos colaterais do tratamento. Os discursos acerca de tais temáticas compõem a categoria "aspectos da adesão".

\subsection{Aspectos da Adesão}

A questão medicamentos foi tema recorrente no discurso dos pacientes. O sujeito numero 1 refere ter dificuldade em inserir a medicação em seu cotidiano, queixa-se das limitações impostas pelos horários rigorosos e a falta de liberdade como consequência do tratamento:

[...] é só o que me corrói [...] O que eu não me conformo é ter que tomar remédio [...] O que acontece, às vezes você vai viajar, vai pra algum lugar, ou você esta trabalhando, aí tem aquele período que você acaba esquecendo [...] Tem que ficar sem se alimentar por um tempo [...] Porque meu trabalho não é aquele que você senta e espera o horário e chega pra almoçar, entendeu? Meu horário é assim, uma coisa estabanada [...] (S.1) 
As dificuldades em relação à medicação parecem se relacionar com a disposição para modificar o estilo de vida e lidar de outra forma com as exigências do tratamento (LEITE; VASCONCELOS, 2003). Ao mesmo tempo em que admite esquecer a medicação, o sujeito reconhece a necessidade de seguir a prescrição e modificar seu ritmo de vida:

Aí pode ser que tome jeito também, né? Porque tem que tomar remédio, né? A gente tem obrigação de lembrar, mas é uma coisa meio chata [...] (S.1)

Corroborando a discussão proposta por Leite e Vasconcelos (2003) sobre a mudança do estilo de vida por conta do tratamento, o paciente aponta ainda já apresentar diferenças em seu comportamento. Segundo ele, em sua vida sempre teve dificuldades em lidar com regras, mas o transplante exige uma reorganização que pode the trazer benefícios: "É como prêmio para melhora a saúde e ganhar a vida, ficar mantendo a vida e a saúde, né?" (S1)

A medicação é apresentada como uma tarefa difícil em contraste com atividades prazerosas da vida proporcionadas pelo transplante:

[...] pra você memorizar o remédio, é uma coisa muito difícil [...] Mas o resto não [...] O resto é vida, né? Não me incomoda fazer uma coisa, correr, brincar, às vezes eu brinco por zoeira, e jogar capoeira [...] (S.1)

De acordo com o paciente, a medicação é capaz garantir a vida, mas não faz parte da vida que é representada por todo o resto que pode ser adquirido a partir do remédio.

Leite e Vasconcelos (2003) destacam o número de medicamentos e o esquema terapêutico prescritos como fatores que dificultam a adesão. Em relação a esses aspectos apontados pelas autoras, um paciente expressa que houve a interrupção do uso da medicação e desrespeito aos horários da alimentação, nas palavras deste, porque "tava de saco cheio do remédio, num tava aguentando mais [...]" (S.2). O paciente em questão é um adolescente. De acordo com Berquist et al. (2008) os índices de não adesão são maiores na população de adolescentes quando comparada a adultos e crianças. Estes resultados estariam relacionados ao fato de os adolescentes perceberem-se saudáveis e menos vulneráveis aos efeitos adversos e considerarem a adesão estrita como algo não tão importante. Assim como os pacientes do referido estudo, o adolescente entrevistado interrompeu o tratamento medicamentoso sem a aquiescência de sua responsável.

Annunsiato, et al. (2007) realizou estudo sobre adesão em pacientes que transitaram do atendimento em serviço de transplante pediátrico ao serviço de transplante adulto. Sua pesquisa aponta haver 0 
declínio no nível de adesão quando acontece essa transição. O estudo atribui esse fato à adolescência e à transição de serviço em si, esse é outro aspecto particular do entrevistado número 2 .

Os efeitos adversos da medicação imunossupressora também foram mencionados pelos sujeitos. Durante o período de investigação de quais pacientes seriam inclusos na pesquisa, a equipe de saúde indicou um paciente (S.5) por questionar o real seguimento ao esquema terapêutico. Questionado o seu baixo nível de escolaridade, entretanto, o paciente refere esquemas de organização que 0 auxiliam. No entanto não refere qualquer aspecto de não adesão em seu discurso, também não se contradiz em suas afirmações como o sujeito número 1 que afirma tomar corretamente a medicação, mas em meio à sua fala admite esquecer o remédio. Devido aos efeitos colaterais o paciente S.5 está perdendo a visão e fazendo hemodiálise. Caso fosse identificada não adesão deste paciente, essa situação estaria associada ao que Leite e Vasconcelos (2003) discutem a partir de conceito proposto por Milstein-Moscati, et al. que chama de "não adesão inteligente à terapêutica", provocada por efeitos colaterais que ocasionam possíveis entraves à adesão.

Um segundo aspecto de adesão pós-transplante citado nas entrevistas foi a frequência as consultas. O Questionário Multidimensional da Adesão no Doente com Transplante Hepático proposto por Correia, et al. $(2007,2008)$ trata desse assunto, por considerar relevante na investigação sobre aderência. O Centro transplantador onde foi realizada a pesquisa também considera esse aspecto significativo, uma vez que um dos critérios usados pelos profissionais para considerar paciente como não aderente é a ausência à consulta marcada no ambulatório.

Dificuldades de acesso são referidas como justificativas para a ausência às consultas. Os pacientes consideram suas justificativas plausíveis para suas faltas, entretanto, para os profissionais da equipe a falta significa não-adesão. Esse é, por conseguinte, um ponto de divergência entre pacientes e profissionais.

A periodicidade das consultas também foi conteúdo das entrevistas, colocada como uma forma de controle para o não consumo de bebida alcoólica. O intervalo de tempo entre os atendimentos dos entrevistados diminuiu após modificações nos exames que apontaram para irregularidades no seguimento das orientações. Dessa forma, a equipe médica pode acompanhar mais de perto como está a evolução clínica dos pacientes. Há também a possibilidade de maior controle dos exames e consequentemente do seguimento de orientações. Os próprios pacientes percebem a mudança para esse acompanhamento mais próximo, e um deles ressalta o controle em relação ao consumo de bebida alcoólica 
Aí eu disse bote só de 3 em 3 meses. É porque eu tenho medo da bebida, sabe? Dá, às vezes dá vontade de tomar uma, num vou dizer pra você que não dá, dá. Às vezes dá vontade de tomar um copo de vinho, me seguro ali. (S.3)

Outro fator incluso na categoria de aspectos da adesão refere-se à dieta. Em relação a esse assunto cada entrevistado abordou de uma forma diferente. Os sujeitos 1 e 2 ressaltaram sua desorganização com os horários da alimentação e da medicação. O sujeito 3 refere que deveria seguir dieta por conta de outras co-morbidades. Já o sujeito 4 afirma que deveria seguir dieta por estar acima do peso. Entrevistados admitem que não seguem como deveriam as orientações relacionadas à dieta, mas dizem que isso seria questão de autocontrole e força de vontade e comprometem-se a seguir indicação.

O médico dá orientação, comer menos, fazer caminhada [...] Jogar uma bolinha é bom! [...] Mas a barriga não deixa! [...] Pois é, mas eu to fazendo dieta, você vai ver! (S.4)

Segundo informações da equipe de saúde, não há restrições alimentares relacionadas ao transplante em si. A necessidade de dieta está relacionada à presença de co-morbidades. Há, ainda, intervalos que devem ser respeitados entre a ingestão de alimentos e de medicação. Uma vez que os pacientes não atendem as indicações referentes a esses aspectos da dieta, caracteriza-se a não adesão. Nos relatos dos pacientes há mostras da dificuldade em seguir a dieta:

O doutor brigou até comigo porque eu disse assim "to comendo até pedra". Ele disse "não senhor, o senhor não pode comer nada que tenha esse negócio de buchada [...]" "Pois, rapaz, é só o que eu como"! Não é nem por causa do transplante, não [...] É por causa do problema de ácido úrico, e eu tenho problema de ácido úrico. Ele disse que se eu comesse vísceras [...] Aí só num como camarão e nem lagosta e eu sou louco por camarão e lagosta. Sei não [...] Se eu comer me ataca mesmo! O ácido úrico [...] Agora, panelada, feijoada isso aí ei como! Eu disse isso para ele. (S.3)

Helman (2003) destaca o aspecto social do alimento que ultrapassa a questão da nutrição. Os alimentos citados podem ser considerados típicos da região onde o paciente vive, marcando a questão social. Apesar de perceber prejuízos para sua saúde ao ingerir tais alimentos o paciente continua consumindo-os, hábito que informa ao médico, o qual Ihe orienta que modifique a dieta: "Ele [médico] disse 'não senhor! Isso o senhor não pode!' Tem que respeitar, né?!" (S.3) Com isso, o paciente assume a posição de seguir a orientação, entretanto 
apenas temporariamente, desconsiderando a necessidade de cuidados constantes.

Aí eu disse que num vou comer mais [...] Aí fiz dieta, passei mais de ano comendo só soja, peixe e peito de frango. 'Destá, quando eu ficar bom vou descontar' Aí hoje eu como! (S.3)

As entrevistas também abordam a relação com os profissionais de saúde. Os resultados demonstram que os pacientes expressaram confiança e segurança na equipe.

[...] o tratamento, aqui, sobre o tratamento dos médicos aqui, eu tenho atendimento sempre fui atendido e procuram muito escutar conversar com a gente, eliminar alguma dúvida ou não, né? Tinha que ter isso.(S.1)

[...] tá muito bem. A equipe médica, ave Maria! Me tratam muito bem, eu também trato eles, todo mundo bem, Ave Maria! Todos os pessoal daqui são maravilhoso! Ave Maria! Devo minha vida a eles. (S.3)

Isso aponta para a importância de estabelecer um vínculo de confiança entre pacientes e profissionais, o que propicia 0 esclarecimento de informações e orientações. Há trabalhos sobre adesão que ressaltam a necessidade de cooperação entre equipe e pacientes para o sucesso do tratamento (CORREIA, 2007, 2008). Por conta disso é importante haver uma relação de parceria entre pacientes e profissionais. O próprio conceito de adesão proposto pela OMS (2003) e alguns outros estudos enfatizam a cooperação entre pacientes e profissionais. Leite e Vasconcelos (2003) discutem a importância do profissional de saúde para a adesão, expondo como o fator mais relevante à adesão a confiança do paciente na prescrição e no profissional. Desta forma a confiança é essencial, pois é algo que influencia a adesão.

\subsection{Significado da Adesão}

A última categoria de análise deste estudo trata do significado de adesão para os entrevistados. Ao serem questionados sobre o que compreendiam por adesão ao tratamento apenas 2 dos entrevistados responderam com segurança à questão. Para o S.1 significa "viver mais". A adesão relaciona-se ainda a sentir-se útil, à expectativa de trabalhar, ter mais possibilidades de futuro. Para o segundo paciente adesão significa seguir o tratamento, caso contrário há um retrocesso. Outro paciente questionou se adesão significaria seguir ou adquirir algo. Enquanto os outros 2 sujeitos não souberam o que responder, dizendo que desconheciam a palavra. 
Isso aponta para um distanciamento entre a linguagem dos pacientes e a utilizada pela equipe de saúde. Leite e Vasconcelos (2003) colocam que em pesquisa realizada com pacientes e profissionais de um centro de transplante em Santa Catarina, descobriu-se que era mais provável que os pacientes seguissem orientações dos auxiliares de saúde, que possuíam uma linguagem mais próxima deles, do que as prescrições médicas.

\section{Conclusão}

A forma como o sujeito se relaciona com as orientações e as insere em seu cotidiano aponta a direção de sua compreensão sobre a adesão ao tratamento. Apesar de os participantes dessa pesquisa terem sido indicados como não aderentes pela equipe de saúde, eles tendem a não se considerar como tal. Alguns deles assumem que eventualmente, ao longo do tratamento, não seguiram as orientações do uso da medicação ou o seguimento da dieta como deveriam, mas atualmente afirmam que o fazem. Outros admitem não seguir a dieta ou faltar à consulta por algum motivo justificável, o que aos olhos dos profissionais caracteriza não adesão.

A partir dessa observação identificamos uma divergência entre os pacientes apontados pela equipe como não aderentes e a maneira como eles falam de si em relação ao seu próprio tratamento: afirmam-se como aderentes, apesar de por vezes admitirem dificuldades relacionadas aos horários de medicação, ganho excessivo de peso, ingestão de alimentos não recomendados. A forma como os pacientes conseguem lidar com as restrições e exigências do tratamento, pode contrariar o que é indicado, mas representa a maneira que encontram para enfrentar e conviver com o adoecimento e o tratamento (REMEN, 1993). Essa divergência remete ao desconhecimento do termo "adesão ao tratamento" por parte de alguns pacientes entrevistados. Como identificar-se com algo que é desconhecido? Como assumir perante os profissionais que exigem algo necessário para a sobrevivência do paciente que tais exigências são negligenciadas? É algo que no discurso dos pacientes mostra-se ambivalente, em momentos assume-se, em outros nega-se:

É, mas religiosamente a medicação [...] Se eu tivesse o principio de rejeição, se eu tivesse rejeição, jamais iria me condenar pelo medicamento. Isso aí é religiosamente [...] Eu não deixo de me preocupar, né? Não sei por que que deu isso [...] Posso ter abusado na comida, né? [...] O que acontece, às vezes você vai viajar, vai pra algum lugar, ou você está trabalhando, aí tem aquele período que você acaba esquecendo [...] (S1) 
No momento que eu tive a rejeição eu não tava seguindo, mas hoje eu digo que sim, sigo o tratamento. (S.2)

Outro fator a ser considerado é há quanto tempo estes pacientes realizaram o transplante. Correia, et al. (2007) referem-se à relação entre o tempo de tratamento e a adesão, indicando que o nível desta é maior logo após a cirurgia e que pode decair à medida que o tempo passa. Berquist (2008) também aponta para essa variação no tocante a aderir ao tratamento no decorrer dos anos. A partir dessa informação é possível referir questionamentos sobre o nível de adesão do paciente com o próprio tratamento e acerca de como sua compreensão da adesão se apresenta após meses ou anos decorridos do início da terapêutica do transplante.

Com o tempo de tratamento pós-transplante variando entre 1 ano e 3 meses a 6 anos, o participantes da pesquisa encontram-se em períodos diversos do tratamento, mas ainda assim apresentam características em comum. Por exemplo, o fato de serem identificados como não-aderentes pela equipe de saúde, que na população estudada independe do tempo transcorrido após o transplante, divergindo dos autores citados acima.

Leite e Vasconcelos (2003) apontam que em algum momento do tratamento o paciente não vai aderir a algum aspecto exigido, o normal é não aderir. Remen (1993), em capítulo tratando do jeito saudável de ter uma doença, aborda diversas situações que sob o olhar da equipe de saúde podem representar má adesão ao tratamento, mas a autora as reconhece como uma maneira de organização do sujeito para enfrentar o adoecimento ou, neste caso, a condição de cuidados crônicos imposta pelo transplante.

Os discursos dos pacientes entrevistados nos fazem concluir que a adesão ao tratamento apresenta diversas nuances que devem ser consideradas para a compreensão do significado atribuído pelos pacientes a este fenômeno.

A compreensão da expressão "adesão ao tratamento" não é algo compartilhado por todos os pacientes entrevistados, mas através de suas vivencias atribuem a ela um sentido expresso em seus discursos. Percebe-se que os entrevistados apresentam uma compreensão particular quanto ao conceito de adesão ao tratamento, que para eles, aderir ou não é algo próprio do sujeito, depende principalmente de sua vontade, de sua natureza e eles possuem uma maneira própria de lidar com as orientações da equipe de saúde.

No momento das entrevistas os pacientes não se assumiram como não aderentes, possivelmente por não compartilharem o mesmo significado de adesão conhecido pelos profissionais de saúde. Leite e Vasconcelos (2003) ressaltam que apenas a relação médico-paciente não explica o fenômeno da não adesão, mas é algo que pode ser trabalhado de maneira a promover maior cooperação por parte dos 
pacientes. Estes não estão preocupados em não seguir prescrições de medicação ou dieta, mas sim em encontrar formas de (re)organizar sua vida da melhor maneira possível (REMEN, 1993), por isso é importante considerar a história do sujeito no momento de fazer exigências que muitas vezes podem parecer sem sentido.

Ao prestar informações e esclarecimentos o profissional de saúde possibilita a inserção de novos hábitos no cotidiano do sujeito. Hábitos como tomar a medicação no horário, alimentar-se no período correto, seguir a dieta, podem ganhar um novo sentido e dessa forma serem integrados à realidade de cada paciente.

\section{Considerações finais}

Leite e Vasconcelos (2003) ressaltam que estudos no campo da adesão medicamentosa desconsideram o paciente como sujeito que ressignifica suas experiências. A expressão "o trem só pega quem anda na linha", utilizada por um paciente, expõe a necessidade de em alguns momentos burlar o tratamento para lidar com a vida tendo de alguma forma controle sobre a situação. Leite e Vasconcelos (2003), e Remen (1993) comentam que o paciente não está preocupado em seguir ou não o tratamento. Seu empenho vai ao sentido de encontrar formas para lidar com o adoecimento ou condição crônica de cuidados de maneira a não trazer maiores prejuízos à sua vida e encontrar um modo mais saudável de conviver com as limitações e exigências que são impostas pela situação vivida.

A percepção da adesão observado nas entrevistas aponta para uma compreensão compartilhada pelos pacientes, sendo esta compreendida como dependente principalmente da vontade de cada um, como se fosse algo intrínseco ao sujeito. Nos discursos analisados há diversos exemplos dessa compreensão por parte dos pacientes que assumem a responsabilidade de seguir ou não o tratamento, muitas vezes desconsiderando outros aspectos relacionados com a adesão e apontados por eles próprios, como por exemplo, a relação com os profissionais e o apoio familiar.

Apesar de se considerarem responsáveis pela adesão, os entrevistados sugeriram estratégias para promoção da adesão. Além de colocarem-se como agentes dessa promoção por transmitirem sua experiência a outros pacientes, ressaltaram a importância de maiores esclarecimentos por parte dos profissionais a respeito de justificativas e necessidades do tratamento, e também a realização de grupos com os pacientes.

Grupos com pacientes transplantados podem representar uma alternativa eficiente para a aproximação entre equipe de saúde e pacientes visando à promoção da adesão ao tratamento. Silveira e Ribeiro (2005) relatam a experiência com grupo de adesão ao 
tratamento, colocando o grupo como um espaço de ensino e aprendizagem para profissionais e pacientes. Com essa forma de intervenção é importante a participação dos diversos profissionais da equipe de saúde, numa perspectiva interdisciplinar, com um planejamento de acordo com as características de cada unidade de saúde onde aconteça o grupo. Nesse tipo de trabalho o paciente é concebido de maneira integral, possibilitando também a ampliação do conceito de saúde-doença ao caracterizar-se como espaço de trocas de experiências que possibilitam aprendizagens (SILVEIRA; RIBEIRO, 2005). Grupos com os pacientes representam uma estratégia interessante para aproximar o conceito, exigências e o cotidiano dos sujeitos.

O presente estudo aponta para uma perspectiva de tratamento que volta seu olhar ao paciente como sujeito que necessita integrar à sua vida exigências imprescindíveis à sua manutenção de sua sobrevida. É preciso que todos estejam engajados na busca pelas melhores condições de vida desses pacientes, que já tem perdas e limitações impostas decorrentes de seu adoecimento e tratamento.

\section{Referências}

BARDIN, L. Análise de conteúdo. Lisboa: Edições 70, 1977.

ANNUNSIATO, R.; EMRE, S.; SCHNEIDER, B.; BARTON, C.; DUGAN, C.; SHEMESH, E. Adherence and medical outcomes in pediatric liver transplant recipients who transition to adult service. Pediatric Transplantation, Palo Alto, v. 12, n. 3, p. 309- 315, 2007.

BERQUIST, R. K.; BERQUIST, W. E.; ESQUIVEL, C. O.; COX, K. L.; WAYMAN, K. L.; LITT, I. F. Non-adherence to post-tx care: prevalence, risk factor and outcomes in adolescent liver tx recipients.

Pediatric Transplantation, Palo Alto, v. 12, p. 194-200, 2008.

COELHO, J. C. U.; PAROLIN, M. B.; MATIAS, J. E. F.; JORGE, F. M. F.; CANAN J r., L. W. Causa de óbito tardio em transplantados de fígado. Revista da Associação Médica Brasileira, Curitiba, v. 49, n. 2, p. 177-180, 2003.

CORREIA, D. T.; BARBOSA, A.; MEGA, I.; BARROSO, E.; MONTEIRO, E. Adesão nos doentes transplantados. Acta Médica Portuguesa, Lisboa, v. 20, p. 73-85, 2007.

CORREIA, D. T.; BARBOSA, A.; MEGA, I.; BARROSO, E.; MONTEIRO, E. Validação do questionario multidimensional da adesão. Acta Médica Portuguesa, Lisboa, v. 21, n. 1, p. 31-36, 2008.

COSTA, V. T.; ALVES, P. C.; LUNARDI, V. L. Viviendo una enfermedad crónica y hablando sobre ser cuidado. Revista de Enfermagem da Universidade Estadual do Rio de J aneiro. [online]. v. 14, n. 1, p. 27-31, nov. 2008. Disponivel em: <http://www.portalbvsenf.eerp.usp.br/scielo.php?script=sci_arttext\& 
pid $=S 0104-35522006000100004 \& \mid n g=e s \& n r m=i s o>$. Acesso em: 16 nov. 2008.

FERREIRA, E. A. P. Adesão ao tratamento em Psicologia pediátrica. In: CREPALDI, M. A.; LINHARES, M. B. M.; PEROSA, G. B. (Orgs.). Temas em Psicologia Pediátrica. São Paulo: Casa do Psicólogo, 2006, p. 147-189.

FREDERICKS, E. M.; LOPEZ, M. J.; MAGEE, J. C.; SHIECK, V.; OPIPARI-ARRIGAN, L. Psychological functioning, nonadherence and health outcomes after pediatric liver transplantation. American J ournal of Transplantation, Ann Arbor, v. 7, p. 1974-1983, 2007. GARCIA, J. H. P.; VASCONCELOS, J. B. M. de; BRASI, I. R. C.; COSTA, P. E. G.; VIEIRA, R.P. G. MORAES, M. O. de. Transplante de fígado: resultados iniciais. Revista do Colégio Brasileiro de Cirurgiões, v. 32, n. 2, p. 100-103, 2005.

LEITE, S. N.; VASCONCELOS, M. da P. C. Adesão à terapêutica medicamentosa: elementos para a discussão de conceitos e pressupostos adotados na literatura. Ciência e Saúde Coletiva, Rio de Janeiro, v. 8, n. 3, p. 775-782, 2003.

ORGANIZAÇÃO MUNDIAL DE SAÚDE (WHO) Adherence to longterm therapies: evidence for action, 2003. Disponível em: <http://www.who.int/chp/knowledge/publications/adhetenceSection 1 .pdf>. Acesso em: 8 nov. 2009.

REMEN, R. N. Uma maneira saudável de ter uma doença. In: REMEN, R. N. (Org.). O paciente como ser humano. São Paulo: Summus, 1993, p. $99-127$.

RODRIGUES, R. T. S.; LIMA, M. das G. S. de; AMORIM, S. F. Transplante renal e hepático: a intervenção psicológica no hospital geral. In: BRUSCATO, W. L.; BERNADETE, C.; LOPES, S. R. (Orgs.). A prática da psicologia hospitalar na Santa Casa de São Paulo: novas páginas de uma antiga história. São Paulo: Casa do Psicólogo, 2004, p. 135-151.

ROMANO, B. W. Princípios para a prática da Psicologia clínica em hospitais. São Paulo: Casa do Psicólogo, 1999.

SILVEIRA, L. M. C., RIBEIRO, V. M. B. Grupo de adesão ao tratamento: espaço de "ensinagem" para profissionais de saúde e pacientes. Interface - comunica, saúde, educação, v. 9, n. 16, p. 91-104, set. 2004 / fev. 2005.

STUBER, M. L.; SHEMESH, E.; SEACORD, D., WASHINGTON, J. III; HELLEMANN, G.; MCDIARMID, S. Evaluating non-adherence to immunosuppressant medications in pediatric liver transplant recipients. Pediatric Transplantation, Palo Alto, v. 12, p. 284-288, 2008.

VIEIRA, A., ROLIM, E. G., De CAPUA Jr, A., SZUTAN, L. A. Recidiva da ingesta alcoólica em pacientes candidatos a transplante hepático: análise de fatores de risco. Arquivos de Gastroenterologia, v. 44, n. 3, p. 205-209, jul./set. 2007. 


\section{Endereço para correspondência \\ Rafaela Tavares Nóbrega}

Rua Capitão Francisco Pedro, 1290, Rodolfo Teófilo, CEP 33668-230, Fortaleza-CE, Brasil

Endereço eletrônico: rafaela_tnobrega@hotmail.com

Marineuza Monteiro da Silva Lucena

Rua Capitão Francisco Pedro, 1290, Rodolfo Teófilo, CEP 33668-230, Fortaleza-CE, Brasil

Endereço eletrônico: marineuza@secrel.com.br

Recebido em: 22/02/2010

Reformulado em: 27/08/2010

Aceito para publicação em: 28/09/2010

Acompanhamento do processo editorial: Ariane Patricia Ewald

\section{Notas}

* Residente de Psicologia Hospitalar do Hospital Universitário Walter Cantídio, Universidade Federal do Ceará-UFCE.

**Preceptora da Residência em Psicologia Hospitalar do Hospital Universitário Walter Cantídio, Universidade Federal do Ceará-UFCE. 